Intraocular pressure

\section{Intraocular pressure in the Middle East}

\section{A Hennis}

\section{A geographical approach to normal IOP interpretation}

A $s$ the demographic transition leads to progressive population ageing globally, this phenomenon coupled with decreases in the burden of infectious disease and subnutrition in the developing world will directly impact on the epidemiology of eye disease. It is expected that while age related cataract will continue to be the leading cause of visual impairment globally, the prevalence of other age related conditions such as primary open angle glaucoma (OAG), macular degeneration, and diabetic retinopathy will increase. ${ }^{1}$ Therefore, age related eye disease will grow in importance, both from clinical and public health perspectives. In spite of this, wide gaps still exist in our knowledge about the epidemiology of ocular disease in many regions across the globe. Ongoing events in the Middle East focus the critical spotlight of world opinion on this region. It is therefore refreshing to learn that an enterprising group of researchers has successfully completed a major epidemiological study of eye disease, which promises to provide much welcomed new and important information (this issue of BJO, p 652). As a result of this body of work, we now have access to the first representative population based data on intraocular pressure (IOP) distribution in a Middle Eastern population.

OAG and elevated IOP are often considered to be inextricably linked, but while up to two thirds of individuals with OAG in population based studies have elevated IOPs (that is, $21 \mathrm{~mm} \mathrm{Hg}$ or higher), relatively few with an elevated IOP have or will in fact develop $\mathrm{OAG}^{2}{ }^{3}$ Elevated IOP is a major risk factor for OAG but other risk factors for these conditions differ, suggesting that the underlying aetiological mechanisms could be different. ${ }^{45}$ Major advances have been made in clarifying relations between IOP and OAG, such that OAG is now defined as a group of diseases characterised by optic neuropathy, irrespective of IOP. ${ }^{6}$ Why then should we wish to learn more about IOP distributions in yet another population? In order to comprehensively manage any disease process, one must be armed with basic epidemiological knowledge about the frequency and distribution of the disease and related risk factors in order to understand the pathophysiology, plan clinical treatment strategies and, at another level, develop optimal public health approaches. The existence of similar risk factors in differing populations aids our understanding of disease aetiology, and it is hoped that the authors will rise to the challenge of presenting truly comprehensive data from their population.

The real potential of the Tehran Eye researchers follow their cohort prospectively

Compared to most published reports, the Tehran Eye Study population was 20 years), and as a result mean IOP was correspondingly lower (14.5 (SD 2.6) $\mathrm{mm} \mathrm{Hg}$ ). Given the obvious age differences, perhaps the comparison of IOP distributions with other epidemiological studies should have been more appropriately restricted to older participants. This is relevant as those aged 40 years and older were noted to have a value for the upper limit of normal IOP (mean IOP (+2 SD) of $20.8 \mathrm{~mm} \mathrm{Hg}$ compared to $23.9 \mathrm{~mm} \mathrm{Hg}$ in the Baltimore Eye Study. ${ }^{7}$ The Tehran Eye Study also confirmed associations between IOP and older age, iris colour, and myopia. Describing the wide variation in IOP distributions across different populations and geographical locations, the authors recommend the use of a "geographical approach to normal IOP interpretation." Several factors may partly explain this variation, including population demographic factors such as age, sex, race; distribution of disease and physical characteristics including blood pressure, pulse rate, diabetes, obesity, myopia, iris colour, nuclear sclerosis, family history of glaucoma; lifestyle factors such as use of alcohol and smoking; and seasonality, as well as probable genetic factors. ${ }^{2}{ }^{4}{ }^{8-12}$ In other words, the paradigm of nature in conjunction with (rather than versus) nurture, and the likely gene-environmental interactions encompassed therein, would explain this variability. Study lies in the future, as the relatively young $(28 \%$ aged less than
Unfortunately the "geographical approach" has not been defined and remains a potential source of controversy. The caveat emptor that caution must be used in interpreting risk factor data based on any form of "geographical approach" must be invoked, given the possible misinterpretation of associations as a result of the ecological fallacy. ${ }^{13}$ Such an approach would be reasonable if it implies that IOP should be defined according to population specific norms or outcomes, ${ }^{14}$ given that IOP varies according to the population distribution of risk factors. The traditional IOP cut point of $21 \mathrm{~mm} \mathrm{Hg}$ may not necessarily be applicable to all populations, ${ }^{2}{ }^{14}$ and in the Tehran study fewer than $0.5 \%$ of participants had IOP levels which exceeded this value. A useful objective of any "geographical approach" could then be investigations to define population specific IOP treatment thresholds, an outcome likely to have both clinical and public health relevance.

The clinical significance of therapies to reduce IOP has now been underpinned by evidence demonstrating that such interventions decrease visual field loss in people with OAG. ${ }^{15}{ }^{16}$ However, conflicting data now exist on their effectiveness to prevent OAG in people with ocular hypertension. ${ }^{17}{ }^{18}$ Nevertheless, data on IOP distributions are necessary to inform public health planning on the prevention of associated visual loss and this will become increasingly relevant as populations age. The real potential of the Tehran Eye Study lies in the future, as the researchers follow their cohort prospectively. Every effort must therefore be made to support their achievement of this objective, given the potential to document the natural history of major eye diseases and further elucidate key risk factors for visual loss. ${ }^{3} 1920$

Br J Ophthalmol 2005;89:647-648

doi: 10.1136/bjo.2005.065813

Correspondence to: A Hennis, Chronic Disease Research Centre University of the West Indies, Bridgetown, Barbados and School of Medicine, Stony Brook University, Stony Brook, NY, USA; ahennis@caribsurf.com

\section{REFERENCES}

1 West S, Sommer A. Prevention of blindness and priorities for the future. Bull World Health Organ 2001;79:244-8.

2 Leske MC. The epidemiology of open-angle glaucoma: a review. Am J Epidemio 1983;118:166-91.

3 Leske MC, Connell A, Wu S, for the Barbados Eye Studies Group, et al. Incidence of open-angle glaucoma. Arch Ophthalmol 2001;1 19:89-95.

4 Wu S-Y, Leske MC, the Barbados Eye Studies Group. Associations with intraocular pressure in the Barbados Eye Study. Arch Ophthalmol 1997; 115: 1572-6.

5 Leske MC, Warheit-Roberts L, Wu S-Y. Openangle glaucoma and ocular hypertension: the 
Long Island Glaucoma Case-Control Study Ophthalmic Epidemiol 1996;3:85-96.

6 Foster PJ, Buhrmann R, Quigley HA, et al. The definition and classification of glaucoma in prevalence surveys. Br J Ophthalmol 2002;86:238-42.

7 Sommer A, Tielsch JM, Katz J, et al. Relationship between intraocular pressure and primary open angle glaucoma among white and black Americans. Arch Ophthalmol 1991;109:1090-5.

8 Weih LM, Mukesh BN, McCarty CA, et al. Association of demographic, familial, medical and ocular factors with intraocular pressure. Arch Ophthalmol 2001;119:875-80.

9 Carel RS, Korczyn AD, Rock M, et al. Association between ocular pressure and certain health parameters. Ophthalmology 1984;91:311-14.

10 Klein BEK, Klein R. Intraocular pressure and cardiovascular risk factors. Arch Ophthalmo 1981;99:837-9.

11 Klein BEK, Klein R, Linton KLP. Intraocular pressure in an American community: the Beaver
Dam Eye Study. Invest Ophthalmol Vis Sci 1992;33:2224-8.

12 Armaly MF. The genetic determination of ocular pressure in the normal eye. Arch Ophthalmol 1967;78: 187-92

13 Schwartz S. The fallacy of the ecological fallacy: the potential misuse of a concept and the consequences. Am J Public Health 1994;84:819-24.

14 Nemesure B, Wu SY, Hennis A, Barbados Eye Studies Group, et al. Factors related to the 4-year risk of high intraocular pressure: the Barbados Eye Studies. Arch Ophthalmol 2003;121:856-62.

15 Heijl A, Leske MC, Bengtsson B, Early Manifest Glaucoma Trial Group, et al. Reduction of intraocular pressure and glaucoma progression: results from the Early Manifest Glaucoma Trial. Arch Ophthalmol 2002;120:1268-79.

16 Collaborative Normal-Tension Glaucoma Study Group. The effectiveness of intraocular pressure reduction in the treatment of normal-tension transplant rejection..$^{5-10}$ Most of these studies have been investigating the potential of recombinant adenovirus as a gene therapy vehicle because of its high transduction efficiency of endothelial cells but not of stroma and epithelial cells. In this issue of $B J O$, Jessup and colleagues ( $p$ 658) expand our knowledge on the in vitro adenovirus mediated gene transfer to the human cornea. They show that human corneas can be efficiently transduced with recombinant adenovirus following up to 28 days in cold storage. Moreover, secreted proteins can be found in the culture medium at high doses over prolonged periods of time. It is obvious that increasing the dose of adenovirus particles per cornea increases the transduction efficiency; however, one has to carefully optimise the dosage since very high doses of adenoviral vectors seem to reduce endothelial cell densities. Moreover, the efficiency of transduction seems to vary greatly resulting in corneas almost resistant against adenoviral transduction ( $<2 \%$ transduction). The reason for this phenomenon is unclear but has been observed in animal models of ex vivo gene transfer of cultured corneas as well ( $T$ Ritter, unpublished observation). The reason for the endothelial cell loss after high dose adenovirus transduction is not clear but adenoviral proteins expressed at low levels in transduced cells or toxic adenoviral capsid proteins following cell entry of adenovirus particles may trigger apoptotic processes and contribute to accelerated cell loss. These problems could be partially circumvented by using third generation adenoviral vectors that do not express adenoviral genes. An important prerequisite for successful gene therapy is based on efficient transgene and protein expression in/ from transduced cells. It is generally accepted that adenovirus mediated gene transfer does not lead to long term gene it should be specifically expressed only in the target cells/tissues without tial of gene therapy on the cornea, focusing on the transduction of the endothelium as a critical target during 
expression because of the episomal status of the adenovirus upon transduction, which is gradually lost during cell divisions. However, since human corneal endothelial cells have lost their capacity to divide (in contrast with rodent corneal endothelial cells) this might not be a severe problem. Moreover, long term gene expression might not be necessary in the transplant situation since short term gene expression might be sufficient to induce immunomodulation. ${ }^{2}$ In addition, long term expression observed in vitro does not necessarily result in long term expression in vivo. First evidence for that has been previously reported showing that transgene expression in vivo is shut off after a few days upon adenovirus mediated gene transfer in vitro. ${ }^{5}$ Finally, results obtained so far in rodent models using ex vivo adenovirus mediated gene transfer for the prevention of corneal graft rejection have not been very successful, ${ }^{71-13}$ except one study using an interleukin-10 expressing adenoviral vector in a sheep model of cornea transplantation. ${ }^{8}$ Whether the low success rate of ex vivo adenovirus mediated gene transfer is a result of the specific environment of the eye leading to loss of transgene expression has to be studied in more detail. Improvements in vectors (low immunogenic ${ }^{14}$ ), promoters (other than viral promoters), and transgenes (it is still not clear which is the best therapeutic gene) have to be accomplished before gene therapy could be considered as an option in cornea gene therapy.

Br J Ophthalmol 2005;89:648-649.

doi: 10.1136/bjo.2005.065854

\section{Authors' affiliations}

T Ritter, Institute of Medical Immunology, Charité-University Medicine Berlin, Germany, and Regenerative Medicine Institute, National University of Ireland, Galway, Ireland

N Gong, U Pleyer, Department of

Ophthalmology, Charité-University Medicine Berlin, Germany

Correspondence to: Thomas Ritter, PhD, Institute of Medical Immunology, CharitéUniversity Medicine Berlin, Campus Mitte, Monbijoustrasse 2a, 10117 Berlin, Germany; thomas.ritter@charite.de

\section{REFERENCES}

1 Edelstein ML, Abedi MR, Wixon J, et al. Gene therapy clinical trials worldwide 1989-2004-an overview. J Gene Med 2004;6:597-602.

2 Anegon I, Guillonneau C, Hill M, et al. Application of gene transfer technologies to transplantation. (Review) Ther Drug Monit 2004;26:248-50.

3 Pleyer U, Dannowski H, Volk H-D, et al. Invited review: Corneal allograft rejection: current understanding. Ophthalmologica 2001;215:254-62.
4 George AJ, Larkin DF. Corneal transplantation: the forgotten graft. (Review) Am J Transplant 2004:4:678-85.

5 Larkin DF, Oral HB, Ring CJ, et al. Adenovirus mediated gene delivery to the corneal endothelium. Transplantation 1996;61:363-70.

6 Oral HB, Larkin DF, Fehervari Z, et al. Ex vivo adenovirus-mediated gene transfer and immunomodulatory protein production in human cornea. Gene Ther 1997:4:639-47.

7 Pleyer U, Bertelmann E, Rieck P, et al. Survival of corneal allografts following adenovirus-mediated gene transfer of interleukin-4. Graefes Arch Clin Exp Ophthalmol 2000;238:531-5.

8 Klebe S, Sykes PJ, Coster DJ, et al. Prolongation of sheep corneal allograft survival by ex vivo transfer of the gene encoding interleukin-10. Transplantation 2001;71:1214-20.

9 Bertelmann E, Ritter T, Vogt K, et al. Efficiency of cytokine gene transfer in corneal endothelial cells and organ cultured corneas mediated by liposomal vehicles and recombinant adenovirus. Ophthalmic Res 2003;35:117-24.

10 Qian Y, Leong FL, Kazlauskas A, et al. Ex vivo adenovirus-mediated gene transfer to corneal graft endothelial cells in mice. Invest Ophthalmol Vis Sci 2004:45:2187-93.

11 Rayner SA, Larkin DF, George AJ. TNF receptor secretion after ex vivo adenoviral gene transfer to cornea and effect on in vivo graft survival. Invest Ophthalmol Vis Sci 2001:42:1568-73.

12 Comer RM, King WJ, Ardjomand N, et al. Effect of administration of CTLA4lg as protein or CDNA on corneal allograft survival. Invest Ophthalmol Vis Sci 2002;43:1095-103.

13 Ardiomand N, McAlister JC, Rogers NJ, et al Modulation of costimulation by CD28 and CD 154 alters the kinetics and cellular characteristics of corneal allograft rejection. Invest Ophthalmol Vis Sci 2003;44:3899-905.

14 Hudde T, Rayner SA, De Alwis M, et al. Adenoassociated and herpes simplex viruses as vectors for gene transfer to the corneal endothelium. Cornea 2000;19:369-73.

\section{"Heavy oil" for intraocular tamponade in retinal detachment surgery}

\section{R B Bhisitkul, V H Gonzalez}

\section{Thicker than water}

I this issue of BJO ( $\mathrm{p}$ 662) Wong and colleagues present data from a prospective pilot study on the use of a long acting, heavier than water internal tamponade agent, Densiron-68, for retinal detachment (RD) repair. Some time ago $^{1}$ we drew up a retinal surgeon's wish list of vitreoretinal agents and adjuncts that are currently sorely lacking in surgical technology, including enzymatic vitreolysis, and antifibroproliferative drugs. Looming large on that wish list was a long acting heavier than water tamponade agent. Long coveted by vitrectomy surgeons, extended tamponade with heavy liquids would at last allow us to address the well recognised limitations of current tamponade agents, limitations that are for the most part imposed by gravity. Now, long acting inferior tamponade with "heavy oil" may soon be at hand, as described in this article.

The era of intraocular tamponade was ushered in with the introduction of air tamponade and then long acting gases $\left(\mathrm{C}_{3} \mathrm{~F}_{8}, \mathrm{SF}_{6}\right)$ and silicone oil. But these are all lighter than water agents that float upwards in the aqueous environment of the eye, leaving inferior retinal breaks exposed, at least with any feasible postoperative head positioning short of suspending patients upsidedown for days and weeks (yes, it has been tried). The inferior retina is critical in retinal detachment surgery, as it often harbours not only retinal tears but proliferative vitreoretinopathy (PVR) membranes, and is the typical site for performing large relaxing retinectomies. Heavier than water agents are available to us in the form of perfluorocarbon liquids such as perfluoro-n-octane (PFO) and perfluorodecalin. First developed by Chang and colleagues, ${ }^{2}$ perfluorocarbon liquids are invaluable tools for manipulating the retina and displacing subretinal fluid intraoperatively. But these agents are not left in the eye for postoperative tamponade because of risks of toxicity, suggested by animal studies but as yet unproved in human patients. ${ }^{3}$ Up to this point, there is simply been no way of getting around gravity, and tamponade of the inferior retina has been a frustrating gap in repair of retinal detachment.

Attempts to overcome this limitation are under way. For example, in a preliminary report of a prospective, uncontrolled pilot study, PFO has been tested in primary RD repair as a medium term tamponade agent for approximately 2 weeks in duration. ${ }^{4}$ Success 
rates with medium term PFO were encouraging, and significant retinal toxicity was not observed, but incomplete removal of PFO was an issue, as was cataract formation and glaucoma.

In their uncontrolled pilot study of 42 eyes, Wong and colleagues describe the use of Densiron-68 for complex RD cases with inferior retinal breaks and PVR. The surgical outcomes were promising, with $81 \%$ successful reattachment with a single surgery and mean duration of tamponade of 72 days. Densiron-68 is a novel tamponade agent composed of perfluorohexyloctane, a semifluorinated alkane with a specific gravity of $1.35 \mathrm{~g} / \mathrm{cm}^{3}$, solubilised in $5000 \mathrm{cS}$ silicone oil. This "heavy oil" has a specific gravity of $1.06 \mathrm{~g} / \mathrm{cm}^{3}$, and has a higher viscosity than perfluorohexyloctane to reduce postoperative emulsification.

In a previous multicentre clinical study, perfluorohexyloctane used as a sole agent was reported to be effective for the management of complicated retinal detachments for up to 3 months of long term tamponade. ${ }^{5}$ However, significant emulsification of pure perfluorohexyloctane was observed, which can result in dispersion of the agent to undesired locations and inadequate tamponade as a result of underfilling of the vitreous cavity. For this reason, many retina surgeons currently use long term perfluorohexyloctane in combination with a standard perfluorohydrocarbon gas bubble. By comparison, this study using Densiron-68 found that dispersion of emulsified heavy oil was relatively infrequent, consisting of minor droplet formation in the anterior chamber and inferior vitreous cavity. Elevated intraocular pressure was associated with its use; short term glaucoma was seen in $14 \%$ of cases, and in $7 \%$ pressures remained elevated at the end of the study.

Ongoing trials based in Cologne, Germany, will compare the efficacy of Densiron-68 and standard silicone oil in the management of complicated retinal detachment. And novel applications may be developed once heavy oils are more widely used, such as for macular hole surgery to eliminate the need for face down head positioning postoperatively. In the meantime, further work will be necessary to evaluate potential issues of retinal toxicity, cataract formation, oil emulsification, and glaucoma risk with the use of this new class of compounds.
Br J Ophthalmol 2005;89:649-650.

doi: $10.1136 /$ bjo.2004.057182

\section{Authors' affiliations \\ R B Bhisitkul, UCSF Beckman Vision Center 10 Koret Way, K301, San Francisco, CA 94143, USA \\ V H Gonzalez, Valley Retina Institute, 1309 E Ridge Road, McAllen, TX 78503, USA}

Correspondence to: Robert Bhisitkul, MD, PhD, UCSF Beckman Vision Center, 10 Koret Way, K301, San Francisco, CA 94143, USA; bhisit@ itsa.ucsf.edu

\section{REFERENCES}

1 Bhisitkul RB. Anticipation for enzymatic vitreolysis. Br J Ophthalmol 2001;85:1-2.

2 Chang $\mathrm{S}$, Ozmert E, Zimmerman NJ. Intraoperative perfluorocarbon liquids in the management of proliferative vitreoretinopathy. Am J Ophthalmol 1988;106:668-74.

3 Chang S, Sparrow JR, Iwamoto T, et al. Experimental studies of tolerance to intravitreal perfluoro-n-octane liquid. Retina perfluoro-n-octane

4 Charles S. Medium term PFO tamponade for selected retinal detachments. Retina Society 37 th Annual Meeting, Baltimore, MD, USA, 30 September-3 October, 2004.

5 Kirchhof B, Wong D, Van Meurs J, et al. Use of perfluorohexlyoctane as a long-term internal tamponade agent in complicated retinal detachment surgery. Am J Ophthalmol 2002;133:95-101.

\section{$\mathrm{ECHO}$}

\section{M3R autoantibodies mark out Sïgren's syndrome}

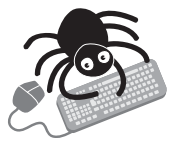

Please visit the British Journal of Ophthalmology website [www. bjophthalmol. com] for a link to the full text of this article. apanese researchers have found what could be a new marker for Sjögren's syndrome (SS) in autoantibodies to an antigen expressed in tear and salivary glands. In time it may be possible to determine how these are linked to the development of the disease.

The researchers looked for the autoantibodies in serum from 426 patients with one of a range of autoimmune diseases and from 128 controls to work out whether these were more prevalent in SS. These were antibodies against a synthetic peptide homologous with the second extracellular domain of the M3 muscarinic acetylcholine receptor (M3R), which has an important role in intracellular signalling.

M3R autoantibodies were significantly associated with patients who had primary (9\%) or secondary (14\%) SS but virtually absent in patients with rheumatoid arthritis, systemic lupus erythematosus, and the controls. Furthermore, the proportions of patients positive or negative for M3R antibodies and positive for SSA and SSB antibodies, rheumatoid factor, and antinuclear factor disclosed that the antibody was associated with patients with SSB antibody (M3R+SSB+, 29\%; M3R-SSB+, 6\%). Clinical features were no different between patients with SS positive or negative for M3R autoantibodies.

The main feature of SS is infiltration of secretory glands by T lymphocytes, which react with various receptors. M3R is a candidate receptor for autoantibodies, as it is expressed in tear and salivary glands, whose function diminishes in patients with SS. Human antibodies against the second extracellular domain of M3R reduce secretion in mice and have been shown to trigger enzyme activity coupled to tear glands.

$\Delta$ Naito Y, et al. Annals of the Rheumatic Diseases 2005;64:510-511. 